\title{
Review Article \\ Controlling Redox Status for Stem Cell Survival, Expansion, and Differentiation
}

\author{
Sébastien Sart, ${ }^{1}$ Liqing Song, ${ }^{2}$ and ${\text { Yan } \mathrm{Li}^{2}}^{2}$ \\ ${ }^{1}$ Hydrodynamics Laboratory, CNRS UMR 7646, Ecole Polytechnique, 91120 Palaiseau, France \\ ${ }^{2}$ Department of Chemical and Biomedical Engineering, FAMU-FSU College of Engineering, Florida State University, \\ 2525 Pottsdamer Street, Tallahassee, FL 32310, USA
}

Correspondence should be addressed to Yan Li; yli@eng.fsu.edu

Received 12 September 2014; Accepted 6 December 2014

Academic Editor: Tullia Maraldi

Copyright (C) 2015 Sébastien Sart et al. This is an open access article distributed under the Creative Commons Attribution License, which permits unrestricted use, distribution, and reproduction in any medium, provided the original work is properly cited.

\begin{abstract}
Reactive oxygen species (ROS) have long been considered as pathological agents inducing apoptosis under adverse culture conditions. However, recent findings have challenged this dogma and physiological levels of ROS are now considered as secondary messengers, mediating numerous cellular functions in stem cells. Stem cells represent important tools for tissue engineering, drug screening, and disease modeling. However, the safe use of stem cells for clinical applications still requires culture improvements to obtain functional cells. With the examples of mesenchymal stem cells (MSCs) and pluripotent stem cells (PSCs), this review investigates the roles of ROS in the maintenance of self-renewal, proliferation, and differentiation of stem cells. In addition, this work highlights that the tight control of stem cell microenvironment, including cell organization, and metabolic and mechanical environments, may be an effective approach to regulate endogenous ROS generation. Taken together, this paper indicates the need for better quantification of ROS towards the accurate control of stem cell fate.
\end{abstract}

\section{Introduction}

Mesenchymal stem cells (MSCs) and pluripotent stem cells (PSCs), including embryonic stem cells (ESCs) and induced pluripotent stem cells (iPSCs), have emerged as important tools for drug screening, disease modeling, and tissue engineering $[1,2]$. MSCs are progenitors of connective tissues, bearing differentiation potential along osteoblasts, chondrocytes, and adipocytes [3]. MSCs are now evaluated in more than 400 clinical trials due to their differentiation potential and especially their trophic activities (i.e., the secretion of antiapoptotic, anti-inflammatory, and antiscarring factors), which constitute their major therapeutic effects in vivo [1]. Different from MSCs, ESCs are derived from inner mass of the blastocyst and iPSCs are obtained by reprogramming somatic cells to ESC-like pluripotent state by overexpression of the pluripotent genes [4]. Both cell populations have differentiation potential for a large spectrum of somatic cell types, mimicking the embryonic development. However, there is still a limited control of lineage-specific differentiation, which impedes the high promise of PSCs for the treatment of incurable diseases [5]. For MSCs, the limited efficacy of MSCs in vivo also indicates the need to improve their therapeutic functions in vitro prior to transplantation [6].

Once injected into damaged tissues, stem cells are exposed to acute ischemia and oxygen deprivation, which lead to the production of highly oxidizing compounds, known as reactive oxygen species (ROS). Excessive ROS would result in the apoptosis of the transplanted cells [7]. Similarly, exposure of stem cells to extreme culture conditions in vitro (such as starvation, metabolic alterations, and exposure to toxic molecules) also leads to the apoptosis mediated by ROS $[8,9]$. Thus, ROS has been recognized as pathological metabolic agents that reduce stem cell functions. However, recent studies have challenged this dogma by demonstrating the positive effects of physiological ROS for the regulation of stem cell fate decision. For instance, hypoxia results in mild levels of ROS (e.g., 1.8-fold of normal level), which are actively involved in the regulation of proliferation and differentiation of MSCs and PSCs [10, 11]. Moreover, 
the metabolic shift observed during stem cell commitment leads to the increased levels of ROS which are intrinsically linked with the differentiation stage of stem cells [12]. Hence, it is becoming clear that physiological levels of ROS play a role of secondary messengers in the regulation of stem cell fate. As a consequence, the control of ROS generation could lead to efficient stem cell expansion and differentiation.

This review investigates recent advances in the understanding of ROS generation and the mechanisms to sustain the redox equilibrium in MSCs and PSCs. In addition, this paper underlines how ROS positively or negatively interferes with the signaling pathways that regulate stem cell survival, proliferation and differentiation. Novel strategies for the tight regulation of stem cell microenvironment which enables the modulation of cellular redox status to control stem cell fate are also discussed.

\section{ROS Generation and Scavenging in Stem Cells}

Stem cell physiology and metabolism are tightly regulated by oxidation-reduction events that mainly occur during respiratory chain. To maintain the redox equilibrium, the oxidative status in stem cells is regulated by the controlled balance of ROS production and scavenging, through the generation of endogenous antioxidants. Therefore, understanding the cellular redox state is important to modulate stem cell survival, expansion, and differentiation.

2.1. ROS Generation in Stem Cells. ROS is mainly produced in mitochondria of the cells. The primary source of mitochondrial ROS is the leakage of a small fraction of respiratory chain electrons (1-2\%), which react with molecular $\mathrm{O}_{2}$ to form superoxide ions $\mathrm{O}_{2}{ }^{-\bullet}$, a precursor of various types of ROS (Figure 1(a)) [13]. The dismutation of $\mathrm{O}_{2}{ }^{-\bullet}$ generates $\mathrm{H}_{2} \mathrm{O}_{2}$ and this reaction is catalyzed by superoxide dismutases (SOD) such as MnSOD [13]. Several mitochondrial complexes of the electron transport chain contribute to the ROS generation in MSCs and PSCs. Complex I is composed of nicotinamide adenine dinucleotide phosphate (NADPH) oxidases (NOXs) [13], the transmembrane proteins that catalyze the oxidation of NAPDH (Figure 1(b)). NOX-1 and NOX-4 are the most expressed NOX isoforms in MSCs and PSCs, and these enzymes significantly contribute to total ROS generation in the cells $[14,15]$. Importantly, activation of Ras-related C3 botulinum toxin substrate 1 (Rac-1), a Rho GTPase, is required for ROS generation mediated by NOXs [16]. Complex II comprises succinate dehydrogenases, which are expressed at significant levels in undifferentiated MSCs and PSCs $[17,18]$. Succinate dehydrogenase catalyzes the oxidation of succinate to fumarate. This reaction is mediated by the conversion of flavin adenine dinucleotide (FAD) to FADH2, where the intermediary electron transfer promotes ROS generation [19]. Complex III contains the ubiquinolcytochrome $c$ reductases, which catalyze the reduction of cytochrome $\mathrm{c}$ by the oxidation of coenzyme Q (Figure 1(c)). The electron leakage from the reduction of cytochrome $\mathrm{c}$ leads to the ROS generation [13]. Therefore, treatment of
PSCs and MSCs with antimycin A (a cytochrome c reductase inhibitor) increases ROS generation [20, 21]. Complex IV is composed of cytochrome c oxidase, which mediates the oxidation of cytochrome $c$ [13]. While the presence of complex IV has been characterized in PSCs and MSCs [22, 23], limited information is available on its contribution to ROS generation in stem cells.

The specific contribution of each mitochondrial complex to the level of ROS generation in stem cells has not been well understood and thus remains to be further explored. In addition, various metabolic intermediates of oxidative phosphorylation (e.g., 2-oxoglutarate dehydrogenase, pyruvate dehydrogenase, glycerol 3-phosphate dehydrogenase etc.) contribute differently to the level of ROS production in the specified sites of mitochondria [24]. While the ROS are mainly generated from mitochondria, other cellular compartments such as endoplasmic reticulum or lysosomes also contribute to the generation of prooxidative molecules [25]. These additional sources of ROS may also play important roles in the regulation of cellular redox status.

2.2. ROS Scavenging in Stem Cells. To counteract excessive accumulation of ROS, various types of scavengers are generated to regulate the redox homeostasis in stem cells, which include SODs, glutathione peroxidase (Gpx), preoxiredoxins (Prx), and lysosomal catalases (CAT) [26]. SOD enables the conversion of $\mathrm{O}_{2}{ }^{--}$to $\mathrm{O}_{2}$ and $\mathrm{H}_{2} \mathrm{O}_{2}$ by sequential oxidationreduction of metalloproteins (i.e., $\mathrm{Zn}$ or $\mathrm{Mn}$ bound proteins) of the enzyme catalytic sites as well as the concomitant oxidation-reduction of superoxide ions [27]. Gpx enables the $\mathrm{H}_{2} \mathrm{O}_{2}$ reduction, in which seleno-cysteine of the enzyme serves as the substrate [28]. $\mathrm{H}_{2} \mathrm{O}_{2}$ is converted to $\mathrm{H}_{2} \mathrm{O}$ by the oxidation of $\mathrm{N}$-terminal cysteine of Prxs, resulting in the formation of Prx homodimer [29]. Also, $\mathrm{H}_{2} \mathrm{O}_{2}$ reacts with various ferric states of the heme of the catalytic site of CAT, which enables its dismutation in a two-electron redox reaction (Figure $1(\mathrm{c})$ ) [30].

The expression of cystine transporters (i.e., xCT antiporter) plays a key role in maintaining the level of antioxidant synthesis [31]. Indeed, cysteine is the major amino acid source for Gpx synthesis. However, upon oxidation in air, cysteine is converted to cystine. Facilitating the transport of cystine to cytoplasm through $\mathrm{xCT}$ enables the reconversion of cystine to cysteine and consequently the sustained synthesis of Gpx [31]. Moreover, under oxidative stress, the induction of nuclear factor erythroid 2-related factor 2 (Nrf-2), a regulator of the cystine transporter, leads to the increased $\mathrm{xCT}$ expression which results in the enhanced Gpx production [31].

Human MSCs have oxidative defense mechanism and resistance to oxidative stress. For example, MSCs express significant levels of active forms of CAT, GPx, and SOD, which confers the resistance against acute ROS-mediated apoptosis $[32,33]$. Indeed, the knockdown of Gpx reduces the viability when MSCs are exposed to high concentration of $\mathrm{H}_{2} \mathrm{O}_{2}$ [32]. Similarly, the activities of SOD, Gpx, and CAT are significantly diminished in culture medium containing the reduced concentration of selenite [33]. 


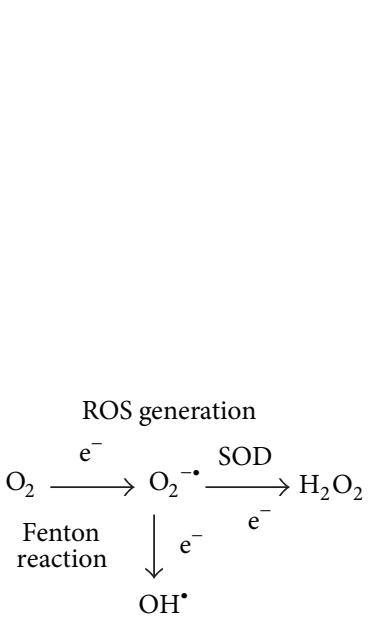

(a)

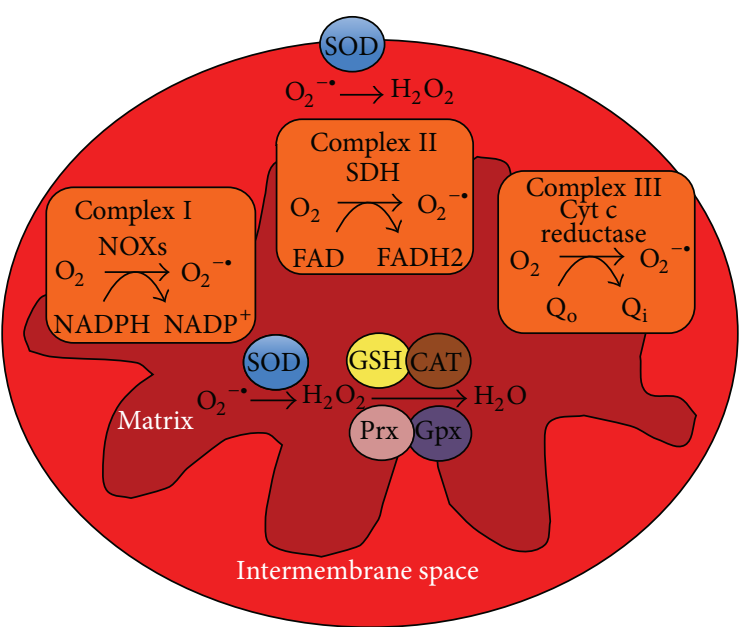

(b)

ROS scavenging

Glutathione peroxidase

$2 \mathrm{GSH}+\mathrm{H}_{2} \mathrm{O}_{2} \longrightarrow \mathrm{GS}-\mathrm{SH}+2 \mathrm{H}_{2} \mathrm{O}$

Catalase

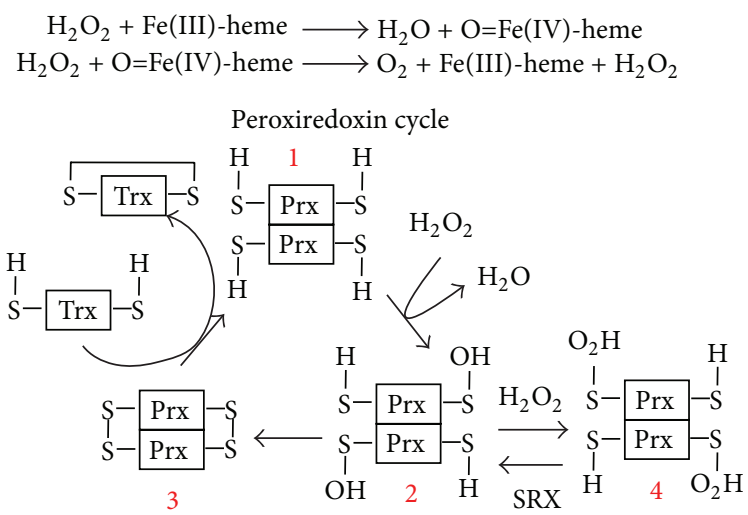

(c)

FIGURE 1: ROS generation and scavenging in stem cells. (a) ROS generation. ROS generation is initiated with the electron transfer to molecular $\mathrm{O}_{2}$, leading to the formation superoxide radicals $\left(\mathrm{O}_{2}{ }^{-\bullet}\right)$, a precursor of the various ROS. Hydroxyl radicals $\left(\mathrm{OH}^{\bullet}\right)$ are generated from $\mathrm{O}_{2}{ }^{-\bullet}$ through a Fenton reaction. Alternatively, SOD catalyzes the formation of hydrogen peroxide $\left(\mathrm{H}_{2} \mathrm{O}_{2}\right)$. (b) ROS are mainly generated at various complex of the respiratory chain, located in the inter-membrane space of the mitochondria. (c) ROS scavenging. The degradation of ROS is catalyzed by scavenging proteins, that is, glutathione peroxidases, catalase, and peroxiredoxin (Prx). Prx are dimers, which contain cysteine (-SH groups) (1). In the presence of $\mathrm{H}_{2} \mathrm{O}_{2}$, the cysteine - $\mathrm{SH}$ groups are oxidized to - $\mathrm{SOH}$ (2), which then condensed to form disulfide groups (S-S) (3). The S-S groups of Prx are reduced by thioredoxin (Trx) to return to the initial -SH form (1). PRX-SOH can be overoxidized by $\mathrm{H}_{2} \mathrm{O}_{2}$ to form Prx-SO $\mathrm{S}_{2} \mathrm{H}$ groups (4).

The enrichment of selenite promotes Gpx and thioredoxin (Trx) activities, leading to the better resistance against oxidative stress induced by $\mathrm{H}_{2} \mathrm{O}_{2}$ [33]. In addition, MSCs express $\mathrm{xCT}$ which enables efficient cystine transport and results in the significant expression of Gpx $[34,35]$. Moreover, upon acute oxidative stress, the activation of Nrf-2 leads to the increased Gpx expression [36].

Undifferentiated PSCs exhibit the increased oxidative defense compared to the differentiated cells [37]. Indeed, ESCs express a significant amount of Gpx-1, which is required to sustain their self-renewal [38]. Also, both human and mouse ESCs express large amounts of Gpx-1, SOD, Prx, and Trx, which are down-regulated during differentiation and are associated with the increased levels of intracellular ROS $[37,39]$. PSCs also express a large amount of Nrf-2, which is down-regulated during spontaneous differentiation [40]. Under oxidative stress, increased Nrf-2 nuclear translocation has been observed in ESCs, which is linked to the enhanced expression of thioredoxin reductase 1, Gpx-1, and Gpx-4 [41]. However, it is suggested that undifferentiated PSCs do not express xCT [31]. As a consequence, PSCs are usually cultivated on feeder layers, which are necessary to provide 
a sufficient amount of cysteine for Gpx expression. Alternatively, addition of $\beta$-mercaptoethanol to the PSC culture medium enables the stabilization of cysteine [31].

\section{Physiological Roles of ROS in Stem Cell Homeostasis}

A tight balance between ROS generation and antioxidant protein synthesis regulates the redox homeostasis in stem cells [42]. Basal levels of ROS are required for the activation of several key cellular pathways for stem cell proliferation and survival. In the meanwhile excessive accumulation of ROS leads to cellular damage.

\subsection{Low Levels of ROS Are Secondary Signaling Messengers for} Cell Proliferation and Survival. Low concentrations of exogenous $\mathrm{H}_{2} \mathrm{O}_{2}$, inhibitors of the mitochondrial electron transfer (e.g., antimycin A, rotenone), and hypoxia induce moderate levels of ROS in MSCs. Low levels of ROS are reported to enhance MSC proliferation and migration through the activation of extracellular-signal-regulated kinases (ERK) 1/2 and Jun-1/2 pathways [43-45]. The positive effects of ROS on MSC expansion are mediated by NOXs. Indeed, the knockdown of NOX-1 and NOX-4 prevents the proliferation of MSCs under hypoxia or upon cultivation in IL-7 containing medium [46]. In addition, growth factors such as platelet-derived growth factor-BB lead to the mild ROS generation which increases the proliferation and migration of adipose-derived MSCs [47]. As recently demonstrated, various mild ROS inducers (i.e., hypoxia, mitochondrial inhibitors, growth factors etc.) converge to activate miR-210, a miRNA that triggers ERK1/2 and AKT activation in MSCs (Figure 2(a)) [47]. Alternatively, moderate levels of ROS regulate the secretory function of MSCs. For instance, the induction of ROS with advanced glycation end products (AGE) is reported to promote the secretion of chemokines (e.g., CCL-2, CCL-4) by MSCs, through the activation of $\mathrm{p} 38$-mitogen-activated protein kinases (MAPK) pathway [48]. Also, hypoxia-induced ROS mediates pro-angiogenic function of MSCs (i.e., secretion of vascular endothelial growth factor (VEGF)) [10]. As reported for various cell types, NOXs may play a role in the trophic function through ROS generation (Figure 2(a)) [49].

Low levels of ROS generated from hypoxia also mediate the proliferation of PSCs, through the enhanced activation of the MAPK, nuclear factor $-\kappa \mathrm{B}(\mathrm{NF}-\kappa \mathrm{B})$, and Wnt signaling (Figure 2(a)) [11, 50]. Moreover, the genetic stability of ESCs requires basal levels of ROS expression [51]. Indeed, the inhibition of ROS generation via acute dose of antioxidants (e.g., CAT) is reported to inhibit the activity of phosphorylated ataxia telangiectasia mutated (pATM), a serine/threonine protein kinase that is activated by DNA double-strand breaks. Inhibition of pATM activity is normally required for maintaining DNA integrity (Figure 2(a)) [51]. Also, the antibacterial function of ESCs is found to be controlled by the sustained expression of NOX-2 [52]. Hence, moderate levels of ROS support important physiological functions in stem cells. In contrast, the abrogation of ROS generation leads to "reductive stress" that significantly alters stem cell homeostasis [53].

3.2. Pathological Levels of ROS Accumulation Lead to Oxidative Stress and Cell Damage. Excessive generation of endogenous ROS and the imbalance between ROS and antioxidant proteins, as well as the culture of stem cells with various extracellular sources of ROS can lead to oxidative stress in stem cells (Figure 2(b)). For examples, aging significantly contributes to endogenously induced redox imbalance in MSCs [54]. The production of AGE, by-products of glycolysis, also leads to oxidative stress in MSCs [55]. In addition, some culture conditions such as the cryopreservation and the irradiation result in acute oxidative damages in PSCs and MSCs through endogenous ROS production [56, 57]. The presence of circulating cell-free DNA in culture medium has also been reported to induce oxidative stress in MSCs [36]. Moreover, exogenous $\mathrm{H}_{2} \mathrm{O}_{2}$ can diffuse through cytoplasmic membrane, leading to the oxidative stress in PSCs and MSCs. Of importance, the paracrine diffusion of endogenous ROS in MSCs has been demonstrated, indicating the propagation of oxidative imbalance at the cellular level [58].

Oxidative stress due to high levels of ROS impairs stem cell homeostasis. Indeed, high levels of ROS disturb MSC adhesion through the down-regulation of the activated focal adhesion kinase (FAK), Src, and the integrin expression (Figure 2(b)) [59]. In addition, oxidative stress leads to DNA damage in MSCs through the induction of the colocalization of ATM, H2A.X, and 53BP1 genes, the specific DNA damage response [60]. Similarly, oxidative stress reduces the telomere length of MSCs by decreasing the expression of telomeric repeat binding factor (TRF) 1 and TRF2 (two proteins involved in telomere elongation and stabilization), leading to the cell senescence (Figure 2(b)) $[60,61]$. In contrast, it has been demonstrated that PSCs are less prone to DNA damage and the senescence induced by oxidative stress, due to the capability for the repair of DNA double-strand breaks $[57,62]$.

Oxidative stress also causes cell cycle arrest in stem cells. High ROS has been found to mediate the activation of p38-MAPK and p16, which inhibits the phosphorylated retinoblastoma $(\mathrm{pRB})$ protein and causes the growth arrest of MSCs [63]. In addition, ROS has been reported to induce growth inhibition through the activation of p53 in MSCs [64]. Similarly, cell cycle arrest can be induced in mouse ESCs under oxidative stress $[57,62]$, as a consequence of c-Jun Nterminal kinase (JNK) and p53 activation (Figure 2(b)) [65].

Finally, excessive levels of ROS promote the apoptosis in MSCs and PSCs $[62,66]$. Indeed, under oxidative stress ROS disrupts mitochondrial cardiolipin-cytochrome c complexes, liberating cytochrome $\mathrm{c}$ in a free form. In addition, ROS induces the BAX-BAK dimerization, enabling the formation of channels on the mitochondrial membrane and thus facilitating the translocation of cytochrome $\mathrm{c}$ to the cytoplasm. The cytoplasmic cytochrome $c$ activates the expression of caspases, leading to apoptosis (Figure 2(b)) [67].

Hence, ROS play dual role in stem cell homeostasis, depending on the level of production. The exact threshold 


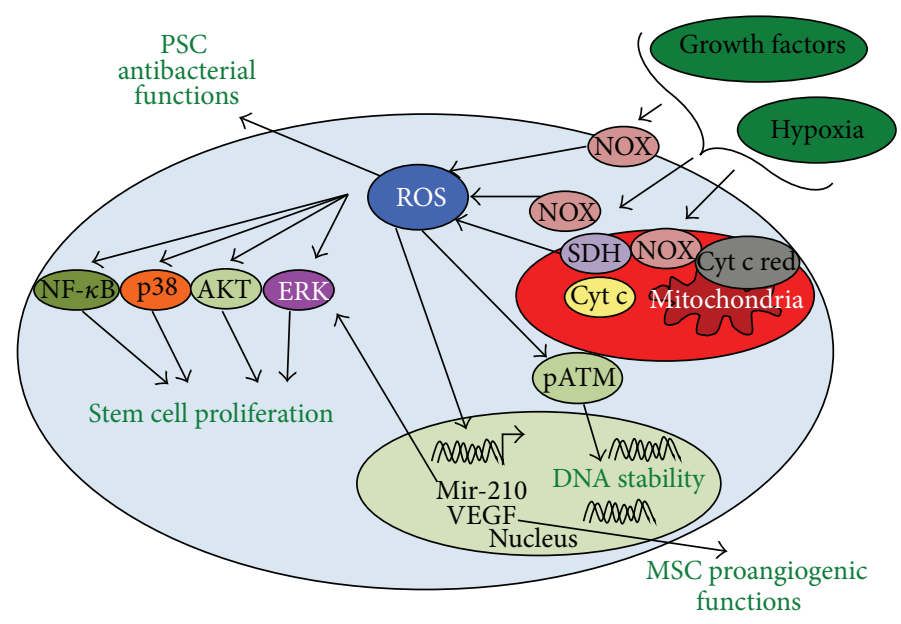

(a)

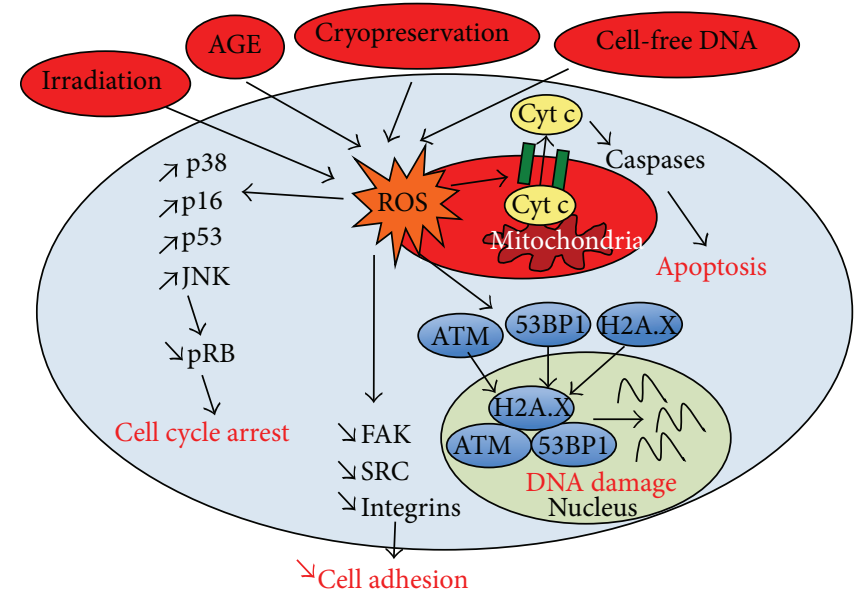

(b)

FIgURE 2: Regulation of stem cell proliferation and survival by ROS. (a) Effect of physiological levels of ROS. Physiological levels of ROS activate various MAPKs (i.e., ERK, p38, and AKT), promoting stem cell proliferation. Mir-210 is upregulated by ROS and is also involved in the MAPK activation, leading to the enhanced stem cell proliferation. Mild levels of ROS promote the activation of pATM, increasing the DNA stability of stem cells. Mild ROS can sustain antibacterial properties of PSCs and the proangiogenic functions of MSCs. (b) Effect of excessive levels of ROS. Excessive levels of ROS induce oxidative stress in stem cells. High levels of ROS result in a decreased stem cell adhesion (i.e., through a decreased activation of FAK-Src signaling) and proliferation (through the reduced activation of pRB). High ROS also reduce DNA stability and induce apoptosis (in favoring BAX-BAK dimerization and the formation of channel facilitating cytochrome $\mathrm{c}$ (cyt c) cytoplasmic translocation). In (a), Cyt c red means Cyt c reductase.

level of ROS to decipher between its role as a secondary physiological messenger or as a source of oxidative stress still needs to be further delineated.

\section{ROS Regulates the Balance between Self-Renewal and Differentiation of Stem Cells}

ROS and the oxidative defense signaling interfere with MSC and PSC differentiation pathways. The regulation of oxidant defense between undifferentiated stem cells and their differentiated progeny indicates the important role of ROS in the regulation of stem cell fate.
4.1. Mesenchymal Stem Cells. MSCs have low numbers of mitochondria at the undifferentiated state, while the increased mitochondrial biogenesis and oxidative phosphorylation (OXPHOS) supercomplexes are observed during differentiation $[18,23]$. Therefore, the redox status is changed upon MSC differentiation and the spontaneous increase in ROS generation occurs during osteogenic and adipogenic differentiation (Figure 3(a)) [68]. However, MSCs display the unique redox profile depending on the differentiation path. For instance, MSCs committed to adipocyte lineage show the increased cysteine redox potential compared to the cells committed to osteoblast lineage [68].

During adipogenic differentiation of MSCs, ROS generation is increased through the mediation by NOX-4 $[69,70]$. 

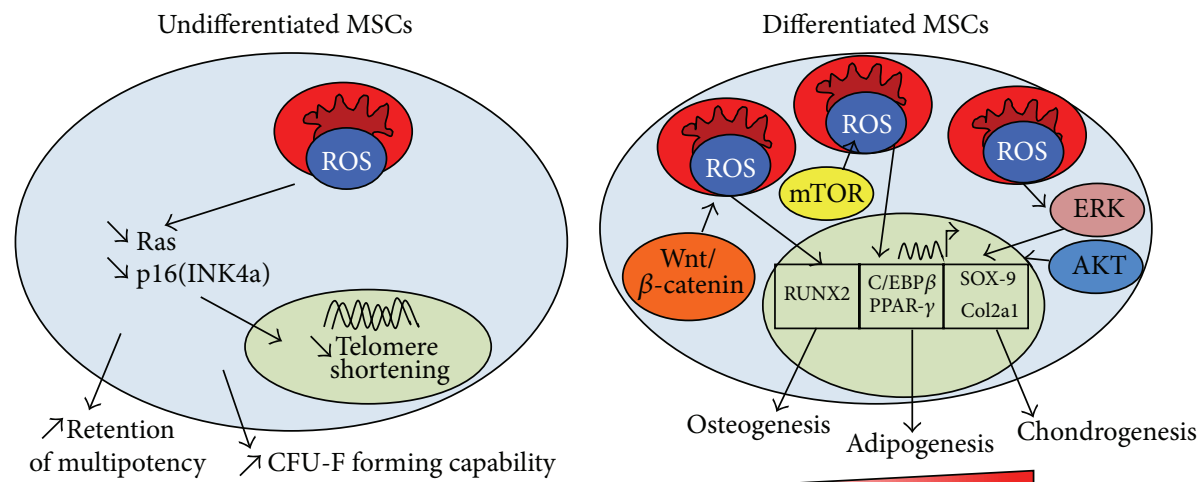

ROS

(a)
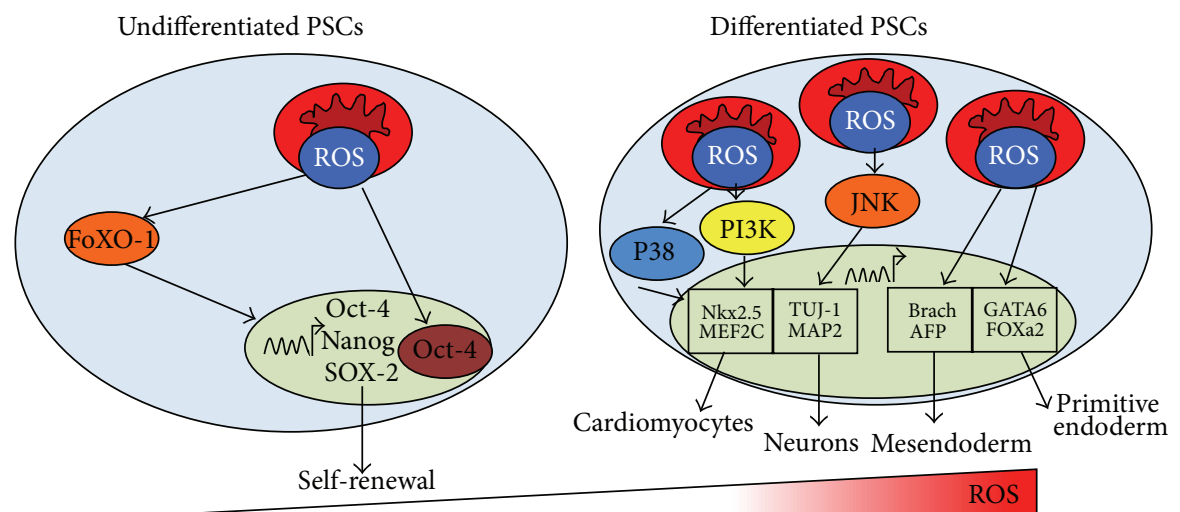

(b)

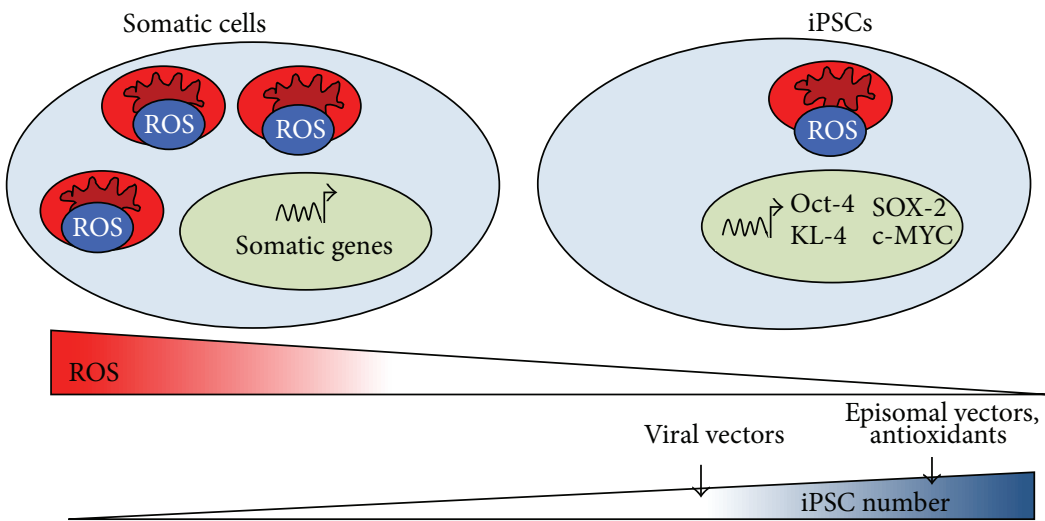

(c)

FIGURE 3: Regulation of stem cell self-renewal, differentiation, and reprogramming by ROS. (a) MSCs. MSCs have low numbers of mitochondria that generate low levels of ROS at undifferentiated state. Low ROS generation sustains the capability of forming colonyforming unit-fibroblasts (CFU-F). Upon differentiation, the number of mitochondria and the ROS levels are increased. ROS promotes the adipogenesis, osteogenesis, and chondrogenesis from MSCs. (b) PSCs. Undifferentiated PSCs have low mitochondrial biogenesis, which increases upon differentiation. Mild levels of ROS promote PSC self-renewal and the expression of Oct-4, NANOG, and SOX-2. Alternatively, the spontaneous and lineage-specific differentiations are associated with the increased ROS generation. For examples, ROS triggers PI3K and p38, which support cardiomyogenic differentiation. ROS also enhances neuronal differentiation through JNK activation. (c) iPSCs. During reprogramming, iPSCs show the decreased mitochondria biogenesis and a reduction of ROS production compared to the somatic cells. Increasing ROS scavenging during reprogramming enhances the efficiency of iPSC generation, which depends on the methods of OKSM (Oct-4, Klf-4, SOX-2, and c-MYC) transfection. 
Inhibition of mitochondrial complex III and complex I significantly reduces the expression of CCAAT-enhancerbinding protein (C/EBP)- $\beta$ and peroxisome proliferatoractivated receptor (PPAR)- $\gamma$, the markers for adipocyte differentiation [69]. However, NOX-4 silencing (by siRNA) did not attenuate C/EBP- $\beta$ or PPAR- $\gamma$ expression but reduced lipid accumulation, indicating the contribution of NOX-4 at late stage of adipogenic differentiation $[69,70]$. Similarly, the activation of mammalian target of rapamycin (mTOR) signaling promotes ROS generation mediated by complex III, which induces the expression of PPAR- $\gamma$ (Figure 3(a)) [15]. To balance the increased ROS expression, adipogenic differentiation is associated with the up-regulation of Forkhead box Os (FoXOs) which regulate the expression of antioxidant enzymes (e.g. catalases, SODs, and Gpxs) [71]. However, Sirt1 (an activator of FoXO-1) reduces adipogenic differentiation potentially by deacetylating PPAR- $\gamma$ or impairing the formation of FoXO-1/PPAR- $\gamma$ complexes [72, 73]. Similarly, Sirt-2 reduces adipogenic differentiation by deacetylating FoXO-1, which promotes nuclear localization of FoXO-1 [74].

During osteogenic differentiation of MSCs, canonical Wnt $/ \beta$-catenin induces ROS generation and plays a critical role in the regulation of MSC differentiation by activating osteogenesis and inhibiting adipogenesis [75]. To balance the ROS effects, the activation of FoXO-1 promotes osteogenic differentiation by regulating the expression of RUNX-2, a master regulatory factor of osteogenesis [76]. Moreover, Sirt-1 enables the deacetylation of $\beta$-catenin and promotes nuclear accumulation of $\beta$-catenin, which acts as a transcription factor of osteogenic genes [77]. The imbalance between the level of ROS and the expression of scavenging proteins can lead to the reduced osteogenic differentiation of MSCs (Figure 3(a)) [78].

ROS generation is also increased during chondrogenic differentiation [79]. ROS produced through NOX-2 and NOX-4 promotes cell survival during chondrogenesis [79]. Moreover, endogenous ROS triggers AKT and ERK signaling, leading to the enhanced expression of SOX-9, collagen type II and the accumulation of proteoglycans (Figure 3(a)) [79]. Sirt-1 is required for chondrogenic differentiation of MSCs through the activation of SOX-9 as well as the deacetylation of NF- $\kappa \mathrm{B}$, leading to the decreased expression of matrix metalloproteinase (MMP)-9, COX-2, and caspase-3 [80]. Finally, the FoXOs enhance the survival of MSCs and prevent the differentiation towards hypertrophic chondrocytes (i.e., indicated by the expression of collagen type X) [81].

4.2. Pluripotent Stem Cells. PSCs display low levels of ROS expression at the undifferentiated state as a consequence of a low level of mitochondrial biogenesis and a high level of ROS scavenging protein expression (e.g. Gpx-1) [38, 82]. The basal levels of ROS are required to sustain the selfrenewal of PSCs [17, 83]. Indeed, it is recently demonstrated that ROS modulates Oct-4 posttranslational modifications (such as sumoylation and ubiquitination), leading to the enhanced nuclear localization of Oct-4 [84]. Sirt-1, a key cell survival factor activated upon ROS exposure, is down-regulated during ROS-induced differentiation through the activity of miR-29b [85]. Sirt-1 also regulates the activation of FoXOs which are required to maintain pluripotency by directly regulating the expression levels of Oct-4, Nanog, and SOX-2 in human ESCs (Figure 3(b)) [86, 87].

The redox status of PSCs changes significantly during spontaneous differentiation. Indeed, ROS expression is increased upon PSC lineage commitment as a consequence of the regulation of scavenging protein expression. For instance, the expressions of Prx-1, SOD2, Gpxs and CAT are found lower in embryoid bodies compared to undifferentiated ESCs $[37,88]$. ROS generation by retinoic acid enables the activation of Wnt signaling through the increased expression of NOXs during extra-embryonic endodermal differentiation (i.e., indicated by the expressions of GATA- 6 and FOXa2) of PSCs $[89,90]$. In addition, ROS generation through the inhibition of glutathione mediates the differentiation of human ESCs towards mesodermal (i.e., indicated by the expression of brachyury, myogenin, and myogenic factor 6) and endodermal lineages (i.e., indicated by the expression of HNF3 $\beta$, AFP, and Sox17) [91]. ROS is found to regulate meso-endodermal specification through the modulation of the MAPKs, such as the inactivation of p38 and AKT as well as concomitant transient increase of JNK and ERK signaling (Figure 3(b)) [91].

ROS also mediates the lineage-specific differentiation of PSCs. For instance, the icariin-induced ROS production through NOX-4 promotes ESC differentiation into cardiomyocytes [92]. ROS can trigger p38 activation and phosphatidylinositol-4,5-bisphosphate 3-kinase (PI3K) expression, which mediate MEF2C nuclear translocation, a key transcription factor in ESC cardiac differentiation [93]. ROS produced during cardiac differentiation is also found to activate NF- $\kappa \mathrm{B}$ signaling and trigger phosphatidylinositol 3-kinase enhancer (PIKE) and PI3K activation [94]. Similarly, ESC differentiation into smooth muscle cells shows the increased ROS production, which mediates the nuclear translocation of serum response factor (SRF), a transcription factor specific for smooth muscle cells [95]. Neural differentiation of ESCs also demonstrates the increased ROS generation through the regulation of antioxidant protein expression [88]. Indeed, it has been recently demonstrated that the Prxs knockdown in mouse ESCs prevents ROS-mediated activation of JNK signaling, which is required for neuronal differentiation (Figure 3(b)) [88].

4.3. Influence of ROS during iPSC Reprogramming. Recently, the reprogramming of somatic cells through forced expression of a set of genes (Oct-4, KL-4, SOX-2, and c-MYC, i.e., OKSM) enables the generation of iPSCs that display ESC-like properties [4]. Both iPSCs and ESCs demonstrate low redox status and the capability for DNA repair following oxidative damage [96]. Importantly, the somatic mitochondria can revert to an ESC-like state in terms of morphology, cellular distribution, and rate of biogenesis after reprogramming (Figure 3(c)) [97].

However, somatic cell reprogramming to derive iPSCs through viral transfection is associated with a high level of ROS which leads to oxidative damage $[98,99]$. The 


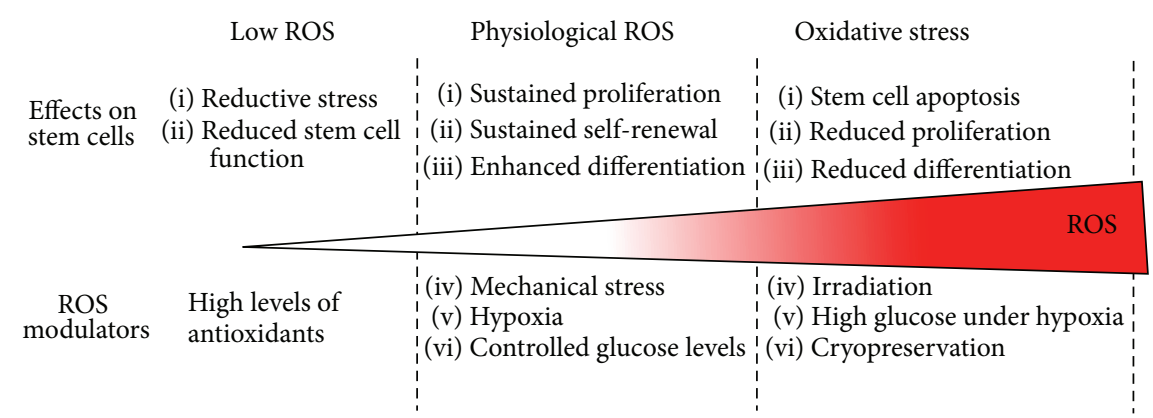

FIGURE 4: Modulation of ROS level regulates the stem cell fate decision. ROS play dual role in stem cell homeostasis, depending on its level of production. At mild levels, ROS serves as a secondary physiological messenger. At high levels, ROS is a source of oxidative stress that leads to cell apoptosis. Tight regulation of biochemical and biomechanical environment can control stem cell oxidative status and thus the stem cell fate decision.

oxidative stress generated during reprogramming impairs cell survival and promotes genetic aberrations $[98,99]$. Addition of antioxidants (such as $\mathrm{N}$-acetylcysteine or vitamin $\mathrm{C}$ ) improves the reprogramming efficiency and reduces genetic abnormalities [98, 99]. Among OKSM genes, c-MYC is reported to be involved in a high level of ROS generation during iPSC derivation [98]. In addition, various methods of reprogramming lead to different levels of ROS generation. For instance, the episomal transfection of OKSM generates lower amounts of ROS than the viral-based reprogramming [100].

Together, ROS play an important role in the regulation of stem cell self-renewal, differentiation and reprogramming. However, the threshold levels for ROS and the regulation of scavenging protein expression to modulate stem cell fates still need to be defined.

\section{Modulation of ROS Generation through Stem Cell Microenvironment}

Stem cell microenvironment including cellular organization and physiological parameters is a potent regulator of ROS generation. Modulating stem cell microenvironment could lead to a better control of redox status for stem cell proliferation and differentiation. The contribution of the respiratory chain in ROS generation suggests the intricate link between stem cell metabolism and ROS generation [101]. In addition, the pathway involving Rac-1 is activated in MSCs and PSCs upon biomechanical stimulation, indicating the relation of mechano-transduction with ROS generation. Thus, tight regulation of biochemical and biomechanical environment can control stem cell oxidative status towards efficient expansion and differentiation (Figure 4).

5.1. Biochemical and Metabolic Regulation of ROS Generation. The metabolism of undifferentiated MSCs and PSCs mainly relies on glycolysis, while a metabolic shift towards OXPHOS is generally observed upon differentiation [12]. The reverse process is also demonstrated during reprogramming where the metabolism of somatic cells shifts from OXPHOS to glycolysis when gaining pluripotency [12]. OXPHOS mediates the production of ROS as a consequence of electron leakage from the respiratory chain. Due to the dominant glycolytic metabolism, undifferentiated MSCs and PSCs generate lower levels of ROS than their differentiated counterparts [101].

Due to the involvement of glucose in metabolic pathways, glucose concentration in the culture medium affects ROS generation in stem cells, through the regulation in the expression of mitochondrial complexes [102]. As a consequence, ROS production is increased when MSCs and PSCs are cultivated in the medium containing a high level of glucose, while the low-glucose medium attenuates the production of ROS and induces antioxidant secretion in MSCs (e.g., MnSOD or catalase) $[102,103]$.

Oxygen tension within the stem cell microenvironment also regulates ROS generation. Low oxygen tension (i.e., hypoxia) favors glycolysis, leading to the reduced ROS production through the metabolism of MSCs and PSCs [104, 105]. However, a rapid transient increase of physiological ROS has been observed under hypoxia. The hypoxia-generated ROS is mediated through the complex III and NOXs which enable the activation of MAPK and the stabilization of hypoxia inducible factors (HIF) to regulate the survival and proliferation of MSCs and PSCs [106, 107]. In addition, hypoxia increases the reprogramming efficiency of somatic cells, potentially due to the reduced oxidative stress and the promotion of glycolysis through the stabilization of HIF-1 $\alpha$ [108].

Interactions between the effects of glucose concentration and oxygen tension are observed for ROS generation in stem cells. Indeed, while low glucose condition reduces the ROS production, high glucose condition in combination with hypoxia induces oxidative stress, impairing the stem cell survival and function such as the secretion of proangiogenic factors [8]. It has been found that high glucose under hypoxia promotes the degradation of HIF- $1 \alpha$ through the increased proteasome activity [8]. All these observations indicate that controlling stem cell metabolic environment can modulate ROS generation.

5.2. Biomechanical Signals Regulate ROS Generation. Rac-1 is a member of Rho-GTPases and is involved in cell-cell and cell-matrix adhesion, the cytoplasmic membrane ruffling, and lamelipodia elongation $[109,110]$. Rac- 1 is found to play 
a key role in the generation of ROS. Indeed, the enzymatic activity of NOXs (i.e., the conversion of NADPH to NADP) is mediated by the interactions of the enzyme's several subunits (p22phox, p47phox, 40phox, and p67phox) and Rac-1 [111]. Consequently, Rac-1 plays a key role in the regulation of PSC and MSC proliferation, migration and differentiation [112114].

The biomechanical environment of PSCs and MSCs (such as surface pattern or stiffness) can modulate Rac-1 activation $[113,115,116]$, which in turn mediates ROS generation. For example, the application of cyclic strains to mouse ESCs promotes ROS generation, which induces cardiomyogenic differentiation $[14,117]$. A gradual increase in ROS generation and a concomitant decrease in SOD expression have been observed when increasing the magnitude of cyclic strain that is applied to MSCs (6 to $24 \%$ magnitude) [118]. The biomechanical regulation of ROS generation in stem cells is an emerging area and needs further exploration.

5.3. Extracellular Matrix and Cell Aggregation as the Modulators of Redox Status. Extracellular matrix (ECM) may bear antioxidant properties that protect stem cells from oxidative damages $[119,120]$. For instance, it has been demonstrated that young endogenous ECM derived from MSCs reduces ROS production compared to old ECM or plastic dishes [119]. The endogenous glycosaminoglycans such as chondroitin sulfate or small leucine-rich proteoglycans have antioxidant properties, which may mediate stem cell oxidative defense $[119,121]$. Alternatively, decellularized ECM from MSCs has been shown to promote the resistance against oxidative stress through the secretion of endogenous antioxidants such as SOD2 [122]. It has been demonstrated that ECM proteins are the targets of ROS through the activation of MMPs, which can affect MSC motility [123].

The formation of MSC aggregates promotes the secretion of ROS scavenging proteins such as SOD2, leading to the increased resistance of MSCs against acute $\mathrm{H}_{2} \mathrm{O}_{2}$ exposure $[124,125]$. The increased secretion of antioxidant proteins might be due to mild hypoxia found in the core of MSC aggregates [124]. Similarly, PSC aggregates can display the increased anti-oxidative defense upon acute ROS generation (e.g., after cryopreservation) [56]. However, the molecular mechanism conferring oxidative defense in stem cell aggregates is still unclear.

\section{Conclusions}

While high levels of ROS have detrimental effects on stem cells through the induction of oxidative stress, physiological levels of ROS play an important role in the regulation of stem cell fate decision. Mild levels of ROS act as secondary messengers by interfering with various signaling pathways that regulate stem cell proliferation, survival, and differentiation. However, the contribution of the specific site of ROS production and the specific type of ROS in the regulation of stem cell fate requires further delineation. In addition, the exact threshold levels of ROS deciphering between the role as damaging molecules or as enhancers of stem cell signaling pathway are not clearly defined. Therefore, methods for the in situ detection of ROS level and the specific species are required to accurately quantify and characterize the threshold level of ROS to modulate stem cell homeostasis. For instance, the application of Raman spectrometry or alternative probes may be preferred to measure intracellular ROS [126]. Combined with accurate ROS measurement, regulation of biochemical and biomechanical environment of stem cells to modulate redox status can lead to the controlled proliferation and differentiation of stem cells towards various biomedical applications.

\section{Abbreviations}

AGE: $\quad$ Advanced glycation end products

CAT: Lysosomal catalase

C/EBP: CCAAT-enhancer-binding protein

CFU-F: Colony-forming unit-fibroblasts

ECM: Extracellular matrix

ESC: $\quad$ Embryonic stem cell

ERK: $\quad$ Extracellular-signal-regulated kinase

FAD: $\quad$ Flavin adenine dinucleotide

FAK: $\quad$ Focal adhesion kinase

FoXOs: Forkhead box Os

Gpx: Glutathione peroxidase

iPSC: Induced pluripotent stem cell

JNK: c-Jun N-terminal kinase

HIF: Hypoxia inducible factor

MAPK: Mitogen-activated protein kinase

MMP: Matrix metalloproteinase

MSC: Mesenchymal stem cell

mTOR: Mammalian target of rapamycin

NADPH: Nicotinamide adenine dinucleotide phosphate

NOXs: NADPH oxidases

NF- $\kappa$ B: $\quad$ Nuclear factor $-\kappa B$

Nrf-2: $\quad$ Nuclear factor erythroid 2-related factor 2

OXPHOS: Oxidative phosphorylation

pATM: Phosphorylated ataxia telangiectasia mutated

pRB: $\quad$ Phosphorylated retinoblastoma protein

PI3K: Phosphatidylinositol-4,5-bisphosphate 3-kinase

PIKE: $\quad$ Phosphatidylinositol 3-kinase enhancer

PPAR: Peroxisome proliferator-activated receptor

Prx: $\quad$ Preoxiredoxin

PSC: $\quad$ Pluripotent stem cell

Rac-1: $\quad$ Ras-related C3 botulinum toxin substrate 1

ROS: $\quad$ Reactive oxygen species

SOD: $\quad$ Superoxide dismutase

SRF: $\quad$ Serum response factor

TRF: Telomeric repeat binding factor

Trx: Thioredoxin

VEGF: Vascular endothelial growth factor.

\section{Conflict of Interests}

The authors declare that there is no conflict of interests regarding the publication of this paper. 


\section{Acknowledgments}

ERC Starting Grant (to Sébastien Sart), FSU start up fund (to Yan Li), and partial support from National Science Foundation (1342192 to Yan Li) are acknowledged.

\section{References}

[1] A. I. Caplan and D. Correa, "The MSC: an injury drugstore," Cell Stem Cell, vol. 9, no. 1, pp. 11-15, 2011.

[2] S. J. Engle and D. Puppala, "Integrating human pluripotent stem cells into drug development," Cell Stem Cell, vol. 12, no. 6, pp. 699-712, 2013.

[3] M. Dominici, K. Le Blanc, I. Mueller et al., "Minimal criteria for defining multipotent mesenchymal stromal cells. The International Society for Cellular Therapy position statement," Cytotherapy, vol. 8, no. 4, pp. 315-317, 2006.

[4] K. Takahashi, K. Tanabe, M. Ohnuki et al., "Induction of pluripotent stem cells from adult human fibroblasts by defined factors," Cell, vol. 131, no. 5, pp. 861-872, 2007.

[5] L. B. Hazeltine, J. A. Selekman, and S. P. Palecek, "Engineering the human pluripotent stem cell microenvironment to direct cell fate," Biotechnology Advances, vol. 31, no. 7, pp. 1002-1019, 2013.

[6] J. Wagner, T. Kean, R. Young, J. E. Dennis, and A. I. Caplan, "Optimizing mesenchymal stem cell-based therapeutics," Current Opinion in Biotechnology, vol. 20, no. 5, pp. 531-536, 2009.

[7] S. Sart, T. Ma, and Y. Li, "Preconditioning stem cells for in vivo delivery," BioResearch Open Access, vol. 3, no. 4, pp. 137-149, 2014.

[8] T. Ishizuka, T. Hinata, and Y. Watanabe, "Superoxide induced by a high-glucose concentration attenuates production of angiogenic growth factors in hypoxic mouse mesenchymal stem cells," Journal of Endocrinology, vol. 208, no. 2, pp. 147-159, 2011.

[9] W. Zhu, J. Chen, X. Cong, S. Hu, and X. Chen, "Hypoxia and serum deprivation-induced apoptosis in mesenchymal stem cells," Stem Cells, vol. 24, no. 2, pp. 416-425, 2006.

[10] S. D. Barros, S. Dehez, E. Arnaud et al., "Aging-related decrease of human ASC angiogenic potential is reversed by hypoxia preconditioning through ROS production," Molecular Therapy, vol. 21, no. 2, pp. 399-408, 2013.

[11] S. H. Lee, Y. J. Lee, and H. J. Han, "Effect of arachidonic acid on hypoxia-induced IL-6 production in mouse ES cells: involvement of MAPKs, NF- $\kappa$ B, and HIF-1 $\alpha$," Journal of Cellular Physiology, vol. 222, no. 3, pp. 574-585, 2010.

[12] S. Sart, S. N. Agathos, and Y. Li, "Process engineering of stem cell metabolism for large scale expansion and differentiation in bioreactors," Biochemical Engineering Journal, vol. 84, pp. 74-82, 2014.

[13] J. F. Turrens, "Mitochondrial formation of reactive oxygen species," The Journal of Physiology, vol. 552, no. 2, pp. 335-344, 2003.

[14] M. Schmelter, B. Ateghang, S. Helmig, M. Wartenberg, and H. Sauer, "Embryonic stem cells utilize reactive oxygen species as transducers of mechanical strain-induced cardiovascular differentiation," The FASEB Journal, vol. 20, no. 8, pp. 1182-1184, 2006.

[15] K. V. Tormos, E. Anso, R. B. Hamanaka et al., "Mitochondrial complex III ROS regulate adipocyte differentiation," Cell Metabolism, vol. 14, no. 4, pp. 537-544, 2011.
[16] G. Cheng, B. A. Diebold, Y. Hughes, and J. D. Lambeth, "Noxldependent reactive oxygen generation is regulated by Racl," Journal of Biological Chemistry, vol. 281, no. 26, pp. 17718-17726, 2006.

[17] S. Varum, A. S. Rodrigues, M. B. Moura et al., "Energy metabolism in human pluripotent stem cells and their differentiated counterparts," PLoS ONE, vol. 6, no. 6, Article ID e20914, 2011.

[18] C.-T. Chen, Y.-R. V. Shih, T. K. Kuo, O. K. Lee, and Y.$\mathrm{H}$. Wei, "Coordinated changes of mitochondrial biogenesis and antioxidant enzymes during osteogenic differentiation of human mesenchymal stem cells," Stem Cells, vol. 26, no. 4, pp. 960-968, 2008.

[19] S. Dröse, "Differential effects of complex II on mitochondrial ROS production and their relation to cardioprotective pre- and postconditioning," Biochimica et Biophysica ActaBioenergetics, vol. 1827, no. 5, pp. 578-587, 2013.

[20] S. L. Pereira, M. Grãos, A. S. Rodrigues et al., "Inhibition of mitochondrial complex III blocks neuronal differentiation and maintains embryonic stem cell pluripotency," PLOS ONE, vol. 8, no. 12, Article ID e82095, 2013.

[21] A. Carrière, T. G. Ebrahimian, S. Dehez et al., "Preconditioning by mitochondrial reactive oxygen species improves the proangiogenic potential of adipose-derived cells-based therapy," Arteriosclerosis, Thrombosis, and Vascular Biology, vol. 29, no. 7, pp. 1093-1099, 2009.

[22] W. Zhou, M. Choi, D. Margineantu et al., "HIF1 $\alpha$ induced switch from bivalent to exclusively glycolytic metabolism during ESCto-EpiSC/hESC transition," The EMBO Journal, vol. 31, no. 9, pp. 2103-2116, 2012.

[23] A. D. Hofmann, M. Beyer, U. Krause-Buchholz, M. Wobus, M. Bornhäuser, and G. Rödel, "Oxphos supercomplexes as a hallmark of the mitochondrial phenotype of adipogenic differentiated human MSCS," PLoS ONE, vol. 7, no. 4, Article ID e35160, 2012.

[24] C. L. Quinlan, I. V. Perevoshchikova, M. Hey-Mogensen, A. L. Orr, and M. D. Brand, "Sites of reactive oxygen species generation by mitochondria oxidizing different substrates," Redox Biology, vol. 1, no. 1, pp. 304-312, 2013.

[25] G. C. Brown and V. Borutaite, "There is no evidence that mitochondria are the main source of reactive oxygen species in mammalian cells," Mitochondrion, vol. 12, no. 1, pp. 1-4, 2012.

[26] S. Pervaiz, R. Taneja, and S. Ghaffari, "Oxidative stress regulation of stem and progenitor cells," Antioxidants and Redox Signaling, vol. 11, no. 11, pp. 2777-2789, 2009.

[27] I. A. Abreu and D. E. Cabelli, "Superoxide dismutases-a review of the metal-associated mechanistic variations," Biochimica et Biophysica Acta-Proteins and Proteomics, vol. 1804, no. 2, pp. 263-274, 2010.

[28] V. Ribas, C. García-Ruiz, and J. C. Fernández-Checa, "Glutathione and mitochondria," Frontiers in Pharmacology, vol. 5, article 151, 2014.

[29] S. Lee, S. M. Kim, and R. T. Lee, “Thioredoxin and thioredoxin target proteins: from molecular mechanisms to functional significance," Antioxidants and Redox Signaling, vol. 18, no. 10, pp. 1165-1207, 2013.

[30] J. Vlasits, C. Jakopitsch, M. Bernroitner, M. Zamocky, P. G. Furtmüller, and C. Obinger, "Mechanisms of catalase activity of heme peroxidases," Archives of Biochemistry and Biophysics, vol. 500, no. 1, pp. 74-81, 2010.

[31] T. Ishii and G. E. Mann, "Redox status in mammalian cells and stem cells during culture in vitro: critical roles of $\mathrm{Nrf} 2$ 
and cystine transporter activity in the maintenance of redox balance," Redox Biology, vol. 2, pp. 786-794, 2014.

[32] A. Valle-Prieto and P. A. Conget, "Human mesenchymal stem cells efficiently manage oxidative stress," Stem Cells and Development, vol. 19, no. 12, pp. 1885-1893, 2010.

[33] R. Ebert, M. Ulmer, S. Zeck et al., "Selenium supplementation restores the antioxidative capacity and prevents cell damage in bone marrow stromal cells in vitro," Stem Cells, vol. 24, no. 5, pp. 1226-1235, 2006.

[34] M. Takarada-Iemata, T. Takarada, Y. Nakamura, E. Nakatani, O. Hori, and Y. Yoneda, "Glutamate preferentially suppresses osteoblastogenesis than adipogenesis through the cystine/glutamate antiporter in mesenchymal stem cells," Journal of Cellular Physiology, vol. 226, no. 3, pp. 652-665, 2011.

[35] M. Iemata, T. Takarada, E. Hinoi, H. Taniura, and Y. Yoneda, "Suppression by glutamate of proliferative activity through glutathione depletion mediated by the cystine/glutamate antiporter in mesenchymal C3H10T1/2 stem cells," Journal of Cellular Physiology, vol. 213, no. 3, pp. 721-729, 2007.

[36] P. Loseva, S. Kostyuk, E. Malinovskaya et al., "Extracellular DNA oxidation stimulates activation of NRF2 and reduces the production of ROS in human mesenchymal stem cells," Expert Opinion on Biological Therapy, vol. 12, no. 1, pp. S85-S97, 2012.

[37] G. Saretzki, L. Armstrong, A. Leake, M. Lako, and T. von Zglinicki, "Stress defense in murine embryonic stem cells is superior to that of various differentiated murine cells," Stem Cells, vol. 22, no. 6, pp. 962-971, 2004.

[38] Q.-Y. Wang, Z.-S. Liu, J. Wang et al., "Glutathione peroxidase1 is required for self-renewal of murine embryonic stem cells," Biochemical and Biophysical Research Communications, vol. 448, no. 4, pp. 454-460, 2014.

[39] G. Saretzki, T. Walter, S. Atkinson et al., "Downregulation of multiple stress defense mechanisms during differentiation of human embryonic stem cells," Stem Cells, vol. 26, no. 2, pp. 455464, 2008.

[40] J. Jang, Y. Wang, H.-S. Kim, M. A. Lalli, and K. S. Kosik, "Nrf2, a regulator of the proteasome, controls self-renewal and pluripotency in human embryonic stem cells," STEM CELLS, vol. 32, no. 10, pp. 2616-2625, 2014.

[41] Z. Huang, J. Li, S. Zhang, and X. Zhang, "Inorganic arsenic modulates the expression of selenoproteins in mouse embryonic stem cell," Toxicology Letters, vol. 187, no. 2, pp. 69-76, 2009.

[42] P. D. Ray, B.-W. Huang, and Y. Tsuji, "Reactive oxygen species (ROS) homeostasis and redox regulation in cellular signaling," Cellular Signalling, vol. 24, no. 5, pp. 981-990, 2012.

[43] J. H. Kim, S.-Y. Song, S. G. Park, S. U. Song, Y. Xia, and J.-H. Sung, "Primary involvement of NADPH oxidase 4 in hypoxiainduced generation of reactive oxygen species in adiposederived stem cells," Stem Cells and Development, vol. 21, no. 12, pp. 2212-2221, 2012.

[44] C. Busletta, E. Novo, L. Valfrè Di Bonzo et al., "Dissection of the biphasic nature of hypoxia-induced motogenic action in bone marrow-derived human mesenchymal stem cells," Stem Cells, vol. 29, no. 6, pp. 952-963, 2011.

[45] S. Li, Y. Deng, J. Feng, and W. Ye, "Oxidative preconditioning promotes bone marrow mesenchymal stem cells migration and prevents apoptosis," Cell Biology International, vol. 33, no. 3, pp. 411-418, 2009.

[46] H. Huang, H. J. Kim, E.-J. Chang et al., "IL-17 stimulates the proliferation and differentiation of human mesenchymal stem cells: Implications for bone remodeling," Cell Death and Differentiation, vol. 16, no. 10, pp. 1332-1343, 2009.

[47] J. H. Kim, S. G. Park, S. Y. Song, J. K. Kim, and J.-H. Sung, "Reactive oxygen species-responsive miR-210 regulates proliferation and migration of adipose-derived stem cells via PTPN2," Cell Death and Disease, vol. 4, no. 4, article e588, 2013.

[48] K. Yang, X. Q. Wang, Y. S. He et al., "Advanced glycation end products induce chemokine/cytokine production via activation of p38 pathway and inhibit proliferation and migration of bone marrow mesenchymal stem cells," Cardiovascular Diabetology, vol. 9, article 66, 2010.

[49] E. C. Chan, F. Jiang, H. M. Peshavariya, and G. J. Dusting, "Regulation of cell proliferation by NADPH oxidase-mediated signaling: potential roles in tissue repair, regenerative medicine and tissue engineering," Pharmacology and Therapeutics, vol. 122, no. 2, pp. 97-108, 2009.

[50] A. Y. Jeong, M. Y. Lee, S. H. Lee, J. H. Park, and H. J. Han, "PPAR $\delta$ agonist-mediated ROS stimulates mouse embryonic stem cell proliferation through cooperation of p38 MAPK and Wnt/ßcatenin," Cell Cycle, vol. 8, no. 4, pp. 611-619, 2009.

[51] T.-S. Li and E. Marbán, "Physiological levels of reactive oxygen species are required to maintain genomic stability in stem cells," Stem Cells, vol. 28, no. 7, pp. 1178-1185, 2010.

[52] A. Finkensieper, M. M. Bekhite, H. Fischer et al., "Antibacterial capacity of differentiated murine embryonic stem cells during defined in vitro inflammatory conditions," Stem Cells and Development, vol. 22, no. 14, pp. 1977-1990, 2013.

[53] J. S. Teodoro, A. P. Rolo, and C. M. Palmeira, “The NAD ratio redox paradox: why does too much reductive power cause oxidative stress?" Toxicology Mechanisms and Methods, vol. 23, no. 5, pp. 297-302, 2013.

[54] M. Kim, C. Kim, Y. S. Choi, C. Park, and Y. Suh, "Age-related alterations in mesenchymal stem cells related to shift in differentiation from osteogenic to adipogenic potential: implication to age-associated bone diseases and defects," Mechanisms of Ageing and Development, vol. 133, no. 5, pp. 215-225, 2012.

[55] S. Kume, S. Kato, S.-I. Yamagishi et al., "Advanced glycation endproducts attenuate human mesenchymal stem cells and prevent cognate differentiation into adipose tissue, cartilage, and bone," Journal of Bone and Mineral Research, vol. 20, no. 9, pp. 16471658, 2005.

[56] S. Sart, T. Ma, and Y. Li, "Cryopreservation of pluripotent stem cell aggregates in defined protein-free formulation," Biotechnology Progress, vol. 29, no. 1, pp. 143-153, 2013.

[57] M. L. Lan, M. M. Acharya, K. K. Tran et al., "Characterizing the radioresponse of pluripotent and multipotent human stem cells," PLoS ONE, vol. 7, no. 12, Article ID e50048, 2012.

[58] M. Rodrigues, O. Turner, D. Stolz, L. G. Griffith, and A. Wells, "Production of reactive oxygen species by multipotent stromal cells/ mesenchymal stem cells upon exposure to fas ligand," Cell Transplantation, vol. 21, no. 10, pp. 2171-2187, 2012.

[59] H. Song, M. J. Cha, B. W. Song et al., "Reactive oxygen species inhibit adhesion of mesenchymal stem cells implanted into ischemic myocardium via interference of focal adhesion complex," Stem Cells, vol. 28, no. 3, pp. 555-563, 2010.

[60] A. Borodkina, A. Shatrova, P. Abushik, N. Nikolsky, and E. Burova, "Interaction between ROS dependent DNA damage, mitochondria and p38 MAPK underlies senescence of human adult stem cells," Aging, vol. 6, pp. 481-495, 2014.

[61] M. Harbo, S. Koelvraa, N. Serakinci, and L. Bendix, “Telomere dynamics in human mesenchymal stem cells after exposure to 
acute oxidative stress," DNA Repair, vol. 11, no. 9, pp. 774-779, 2012.

[62] Y.-L. Guo, S. Chakraborty, S. S. Rajan, R. Wang, and F. Huang, "Effects of oxidative stress on mouse embryonic stem cell proliferation, apoptosis, senescence, and self-renewal," Stem Cells and Development, vol. 19, no. 9, pp. 1321-1331, 2010.

[63] J.-S. Lee, M.-O. Lee, B.-H. Moon, S. H. Shim, A. J. Fornace Jr., and H.-J. Cha, "Senescent growth arrest in mesenchymal stem cells is bypassed by Wipl-mediated downregulation of intrinsic stress signaling pathways," Stem Cells, vol. 27, no. 8, pp. 19631975, 2009.

[64] S. V. Boregowda, V. Krishnappa, J. W. Chambers et al., "Atmospheric oxygen inhibits growth and differentiation of marrowderived mouse mesenchymal stem cells via a p53-dependent mechanism: Implications for long-term culture expansion," Stem Cells, vol. 30, no. 5, pp. 975-987, 2012.

[65] T. D. N. Ngoc, Y.-O. Son, S.-S. Lim et al., "Sodium fluoride induces apoptosis in mouse embryonic stem cells through ROS-dependent and caspase- and JNK-mediated pathways," Toxicology and Applied Pharmacology, vol. 259, no. 3, pp. 329337, 2012.

[66] F. W. Wang, Z. Wang, Y. M. Zhang et al., "Protective effect of melatonin on bone marrow mesenchymal stem cells against hydrogen peroxide-induced apoptosis in vitro," Journal of Cellular Biochemistry, vol. 114, no. 10, pp. 2346-2355, 2013.

[67] C.-C. Wu and S. B. Bratton, "Regulation of the intrinsic apoptosis pathway by reactive oxygen species," Antioxidants and Redox Signaling, vol. 19, no. 6, pp. 546-558, 2013.

[68] B. R. Imhoff and J. M. Hansen, "Differential redox potential profiles during adipogenesis and osteogenesis," Cellular and Molecular Biology Letters, vol. 16, no. 1, pp. 149-161, 2011.

[69] J. H. Kim, S.-H. Kim, S. Y. Song et al., "Hypoxia induces adipocyte differentiation of adipose-derived stem cells by triggering reactive oxygen species generation," Cell Biology International, vol. 38, no. 1, pp. 32-40, 2014.

[70] K. Schröder, K. Wandzioch, I. Helmcke, and R. P. Brandes, "Nox4 acts as a switch between differentiation and proliferation in preadipocytes," Arteriosclerosis, Thrombosis, and Vascular Biology, vol. 29, no. 2, pp. 239-245, 2009.

[71] M. Higuchi, G. J. Dusting, H. Peshavariya et al., "Differentiation of human adipose-derived stem cells into fat involves reactive oxygen species and forkhead box ol mediated upregulation of antioxidant enzymes," Stem Cells and Development, vol. 22, no. 6, pp. 878-888, 2013.

[72] N. Puri, K. Sodhi, M. Haarstad et al., "Heme induced oxidative stress attenuates sirtuinl and enhances adipogenesis in mesenchymal stem cells and mouse pre-adipocytes," Journal of Cellular Biochemistry, vol. 113, no. 6, pp. 1926-1935, 2012.

[73] L. Qiao and J. Shao, "SIRT1 regulates adiponectin gene expression through Foxol-C/enhancer- binding protein $\alpha$ transcriptional complex," Journal of Biological Chemistry, vol. 281, no. 52, pp. 39915-39924, 2006.

[74] E. Jing, S. Gesta, and C. R. Kahn, "SIRT2 regulates adipocyte differentiation through FoxO1 acetylation/deacetylation," Cell Metabolism, vol. 6, no. 2, pp. 105-114, 2007.

[75] D.-Y. Zhang, Y. Pan, C. Zhang et al., "Wnt/ $\beta$-catenin signaling induces the aging of mesenchymal stem cells through promoting the ROS production," Molecular and Cellular Biochemistry, vol. 374, no. 1-2, pp. 13-20, 2013.

[76] C. C. Teixeira, Y. Liu, L. M. Thant, J. Pang, G. Palmer, and M. Alikhani, "Foxol, a novel regulator of osteoblast differentiation and skeletogenesis," Journal of Biological Chemistry, vol. 285, no. 40, pp. 31055-31065, 2010.

[77] P. Simic, K. Zainabadi, E. Bell et al., "SIRT1 regulates differentiation of mesenchymal stem cells by deacetylating $\beta$-catenin," EMBO Molecular Medicine, vol. 5, no. 3, pp. 430-440, 2013.

[78] N. Sun, L. Yang, Y. Li et al., "Effect of advanced oxidation protein products on the proliferation and osteogenic differentiation of rat mesenchymal stem cells," International Journal of Molecular Medicine, vol. 32, no. 2, pp. 485-491, 2013.

[79] S. K. Ki, W. C. Hae, E. Y. Hee, and Y. K. Ick, "Reactive oxygen species generated by NADPH oxidase 2 and 4 are required for chondrogenic differentiation," The Journal of Biological Chemistry, vol. 285, no. 51, pp. 40294-40302, 2010.

[80] C. Buhrmann, F. Busch, P. Shayan, and M. Shakibaei, "Sirtuin-1 (SIRT1) is required for promoting chondrogenic differentiation of mesenchymal stem cells," The Journal of Biological Chemistry, vol. 289, no. 32, pp. 22048-22062, 2014.

[81] H. H. Lee, C. C. Chang, M. J. Shieh et al., "Hypoxia enhances chondrogenesis and prevents terminal differentiation through PI3K/Akt/FoxO dependent anti-apoptotic effect," Scientific Reports, vol. 3, article 2683, 2013.

[82] Y. M. Cho, S. Kwon, Y. K. Pak et al., "Dynamic changes in mitochondrial biogenesis and antioxidant enzymes during the spontaneous differentiation of human embryonic stem cells," Biochemical and Biophysical Research Communications, vol. 348, no. 4, pp. 1472-1478, 2006.

[83] S. Varum, O. Momčilović, C. Castro, A. Ben-Yehudah, J. Ramalho-Santos, and C. S. Navara, "Enhancement of human embryonic stem cell pluripotency through inhibition of the mitochondrial respiratory chain," Stem Cell Research, vol. 3, no. 2-3, pp. 142-156, 2009.

[84] Y. Yao, Y. Lu, W.-C. Chen et al., "Cobalt and nickel stabilize stem cell transcription factor OCT4 through modulating its sumoylation and ubiquitination," PLoS ONE, vol. 9, no. 1, Article ID e86620, 2014.

[85] Z. Xu, L. Zhang, X. Fei, X. Yi, W. Li, and Q. Wang, “The miR29b-Sirtl axis regulates self-renewal of mouse embryonic stem cells in response to reactive oxygen species," Cellular Signalling, vol. 26, no. 7, pp. 1500-1505, 2014.

[86] X. Zhang, S. Yalcin, D.-F. Lee et al., "FOXO1 is an essential regulator of pluripotency in human embryonic stem cells," Nature Cell Biology, vol. 13, no. 9, pp. 1092-1101, 2011.

[87] A. Brunet, L. B. Sweeney, J. F. Sturgill et al., "Stress-dependent regulation of FOXO transcription factors by the SIRT1 deacetylase," Science, vol. 303, no. 5666, pp. 2011-2015, 2004.

[88] S.-U. Kim, Y.-H. Park, J.-M. Kim et al., “Dominant role of peroxiredoxin/JNK axis in stemness regulation during neurogenesis from embryonic stem cells," Stem Cells, vol. 32, no. 4, pp. 9981011, 2014.

[89] L. Sandieson, J. T. K. Hwang, and G. M. Kelly, "Redox regulation of canonical Wnt signaling affects extraembryonic endoderm formation," Stem Cells and Development, vol. 23, no. 10, pp. 10371049, 2014.

[90] J. W. H. Wen, J. T. K. Hwang, and G. M. Kelly, "Reactive oxygen species and Wnt signalling crosstalk patterns mouse extraembryonic endoderm," Cellular Signalling, vol. 24, no. 12, pp. 2337-2348, 2012.

[91] A.-R. Ji, S.-Y. Ku, M. S. Cho et al., "Reactive oxygen species enhance differentiation of human embryonic stem cells into mesendodermal lineage," Experimental and Molecular Medicine, vol. 42, no. 3, pp. 175-186, 2010. 
[92] J. Li, M. Stouffs, L. Serrander et al., “The NADPH oxidase NOX4 drives cardiac differentiation: role in regulating cardiac transcription factors and MAP kinase activation," Molecular Biology of the Cell, vol. 17, no. 9, pp. 3978-3988, 2006.

[93] L. Ding, X.-G. Liang, Y. Hu, D.-Y. Zhu, and Y.-J. Lou, "Involvement of p38MAPK and reactive oxygen species in icariininduced cardiomyocyte differentiation of murine embryonic stem cells in vitro," Stem Cells and Development, vol. 17, no. 4, pp. 751-760, 2008.

[94] L. Zhou, B. Zheng, L. Tang, Y. Huang, and D. Zhu, "Involvement of PIKE in icariin induced cardiomyocyte differentiation from murine embryonic stem cells," Pharmazie, vol. 69, no. 3, pp. 198202, 2014

[95] Q. Xiao, Z. Luo, A. E. Pepe, A. Margariti, L. Zeng, and Q. $\mathrm{Xu}$, "Embryonic stem cell differentiation into smooth muscle cells is mediated by Nox4-produced $\mathrm{H}_{2} \mathrm{O}_{2}$," American Journal of Physiology-Cell Physiology, vol. 296, no. 4, pp. C711-C723, 2009.

[96] L. Armstrong, K. Tilgner, G. Saretzki et al., "Human induced pluripotent stem cell lines show stress defense mechanisms and mitochondrial regulation similar to those of human embryonic stem cells," Stem Cells, vol. 28, no. 4, pp. 661-673, 2010.

[97] A. Prigione, B. Fauler, R. Lurz, H. Lehrach, and J. Adjaye, “The senescence-related mitochondrial/oxidative stress pathway is repressed in human induced pluripotent stem cells," Stem Cells, vol. 28, no. 4, pp. 721-733, 2010.

[98] M. A. Esteban, T. Wang, B. Qin et al., "Vitamin C enhances the generation of mouse and human induced pluripotent stem cells," Cell Stem Cell, vol. 6, no. 1, pp. 71-79, 2010.

[99] J. Ji, V. Sharma, S. Qi et al., "Antioxidant supplementation reduces genomic aberrations in human induced pluripotent stem cells," Stem Cell Reports, vol. 2, no. 1, pp. 44-51, 2014.

[100] N. Mah, Y. Wang, M.-C. Liao et al., "Molecular insights into reprogramming-initiation events mediated by the OSKM gene regulatory network," PLoS ONE, vol. 6, no. 8, Article ID e24351, 2011.

[101] E. Perales-Clemente, C. D. Folmes, and A. Terzic, "Metabolic regulation of redox status in stem cells," Antioxidants \& Redox Signaling, vol. 21, no. 11, pp. 1648-1659, 2014.

[102] T. Lo, J. H. Ho, M.-H. Yang, and O. K. Lee, "Glucose reduction prevents replicative senescence and increases mitochondrial respiration in human mesenchymal stem cells," Cell Transplantation, vol. 20, no. 6, pp. 813-825, 2011.

[103] Y. H. Kim, J. S. Heo, and H. J. Han, "High glucose increase cell cycle regulatory proteins level of mouse embryonic stem cells via PI3-K/Akt and MAPKs signal pathways," Journal of Cellular Physiology, vol. 209, no. 1, pp. 94-102, 2006.

[104] L. B. Buravkova, Y. V. Rylova, E. R. Andreeva et al., "Low ATP level is sufficient to maintain the uncommitted state of multipotent mesenchymal stem cells," Biochimica et Biophysica Acta (BBA)_General Subjects, vol. 1830, no. 10, pp. 4418-4425, 2013.

[105] C. E. Forristal, D. R. Christensen, F. E. Chinnery et al., "Environmental oxygen tension regulates the energy metabolism and self-renewal of human embryonic stem cells," PLoS ONE, vol. 8, no. 5, Article ID e62507, 2013.

[106] M. Calvani, G. Comito, E. Giannoni, and P. Chiarugi, "Timedependent stabilization of hypoxia inducible factor-1alpha by different intracellular sources of reactive oxygen species," PLoS ONE, vol. 7, no. 10, Article ID e38388, 2012.
[107] E. Närvä, J.-P. Pursiheimo, A. Laiho et al., "Continuous hypoxic culturing of human embryonic stem cells enhances SSEA-3 and MYC levels," PLoS ONE, vol. 8, no. 11, Article ID e78847, 2013.

[108] J. Mathieu, W. Zhou, Y. Xing et al., "Hypoxia-inducible factors have distinct and stage-specific roles during reprogramming of human cells to pluripotency," Cell Stem Cell, vol. 14, no. 5, pp. 592-605, 2014.

[109] M. Fukata, M. Nakagawa, and K. Kaibuchi, "Roles of Rho-family GTPases in cell polarisation and directional migration," Current Opinion in Cell Biology, vol. 15, no. 5, pp. 590-597, 2003.

[110] P. M. Duquette and N. Lamarche-Vane, "Rho GTPases in embryonic development," Small GTPases, vol. 5, no. 2, 2014.

[111] P. Kleniewska, A. Piechota, B. Skibska, and A. Gorăca, "The NADPH oxidase family and its inhibitors," Archivum Immunologiae et Therapiae Experimentalis, vol. 60, no. 4, pp. 277-294, 2012.

[112] S. Sart, A. Errachid, Y.-J. Schneider, and S. N. Agathos, "Modulation of mesenchymal stem cell actin organization on conventional microcarriers for proliferation and differentiation in stirred bioreactors," Journal of Tissue Engineering and Regenerative Medicine, vol. 7, no. 7, pp. 537-551, 2013.

[113] A. R. Cameron, J. E. Frith, G. A. Gomez, A. S. Yap, and J. J. Cooper-White, "The effect of time-dependent deformation of viscoelastic hydrogels on myogenic induction and Racl activity in mesenchymal stem cells," Biomaterials, vol. 35 , no. 6, pp. 1857-1868, 2014.

[114] H. N. Suh and H. J. Han, "Laminin regulates mouse embryonic stem cell migration: involvement of Epac1/Rapl and Rac1/cdc42," The American Journal of Physiology-Cell Physiology, vol. 298, no. 5, pp. C1159-C1169, 2010.

[115] L. Gao, R. McBeath, and C. S. Chen, "Stem cell shape regulates a chondrogenic versus myogenic fate through racl and $\mathrm{N}$ cadherin," Stem Cells, vol. 28, no. 3, pp. 564-572, 2010.

[116] L. Mattias, A. Haque, N. Adnan, and T. Akaike, "The effects of artificial E-cadherin matrix-induced embryonic stem cell scattering on paxillin and RhoA activation via $\alpha$-catenin," Biomaterials, vol. 35, no. 6, pp. 1797-1806, 2014.

[117] J. S. Heo and J.-C. Lee, " $\beta$-catenin mediates cyclic strainstimulated cardiomyogenesis in mouse embryonic stem cells through ROS-dependent and integrin-mediated PI3K/Akt pathways," Journal of Cellular Biochemistry, vol. 112, no. 7, pp. 1880-1889, 2011.

[118] R. Li, B. Chen, G. Wang, B. Yu, G. Ren, and G. Ni, "Effects of mechanical strain on oxygen free radical system in bone marrow mesenchymal stem cells from children," Injury, vol. 42, no. 8, pp. 753-757, 2011.

[119] Y. Sun, W. Li, Z. Lu et al., "Rescuing replication and osteogenesis of aged mesenchymal stem cells by exposure to a young extracellular matrix," FASEB Journal, vol. 25, no. 5, pp. 1474$1485,2011$.

[120] G. Fan, L. Wen, M. Li et al., "Isolation of mouse mesenchymal stem cells with normal ploidy from bone marrows by reducing oxidative stress in combination with extracellular matrix," $B M C$ Cell Biology, vol. 12, article 30, 2011.

[121] J. Egea, A. G. García, J. Verges, E. Montell, and M. G. López, "Antioxidant, antiinflammatory and neuroprotective actions of chondroitin sulfate and proteoglycans," Osteoarthritis and Cartilage, vol. 18, no. 1, pp. S24-S27, 2010.

[122] M. Pei, Y. Zhang, J. Li, and D. Chen, "Antioxidation of decellularized stem cell matrix promotes human synovium-derived stem cell-based chondrogenesis," Stem Cells and Development, vol. 22, no. 6, pp. 889-900, 2013. 
[123] S. P. Yun, S.-J. Lee, S. Y. Oh et al., "Reactive oxygen species induce MMP12-dependent degradation of collagen 5 and fibronectin to promote the motility of human umbilical cordderived mesenchymal stem cells," British Journal of Pharmacology, vol. 171, no. 13, pp. 3283-3297, 2014.

[124] S. Sart, A.-C. Tsai, Y. Li, and T. Ma, "Three-dimensional aggregates of mesenchymal stem cells: cellular mechanisms, biological properties, and applications," Tissue Engineering, Part B: Reviews, vol. 20, no. 5, pp. 365-380, 2014.

[125] Q. Zhang, A. L. Nguyen, S. Shi et al., "Three-dimensional spheroid culture of human gingiva-derived mesenchymal stem cells enhances mitigation of chemotherapy-induced oral mucositis," Stem Cells and Development, vol. 21, no. 6, pp. 937947, 2012.

[126] B. Kalyanaraman, V. Darley-Usmar, K. J. A. Davies et al., "Measuring reactive oxygen and nitrogen species with fluorescent probes: challenges and limitations," Free Radical Biology and Medicine, vol. 52, no. 1, pp. 1-6, 2012. 


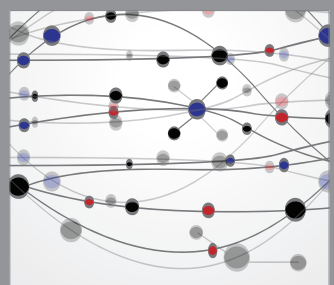

The Scientific World Journal
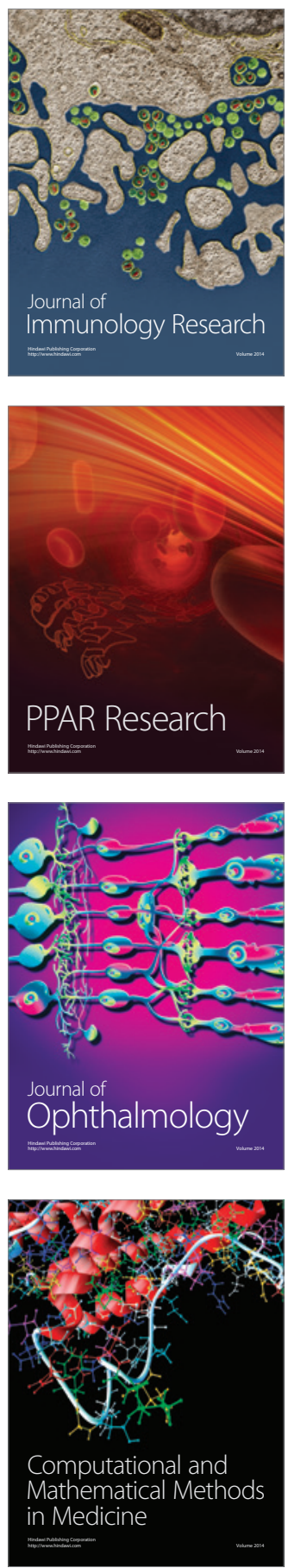

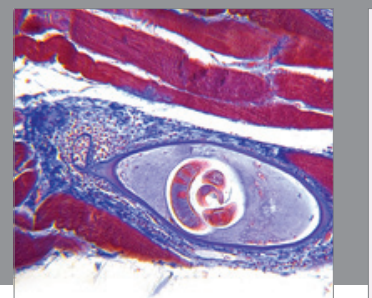

Gastroenterology

Research and Practice
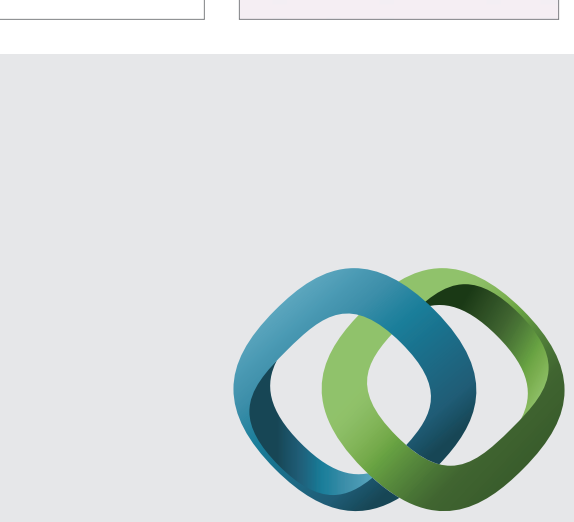

\section{Hindawi}

Submit your manuscripts at

http://www.hindawi.com
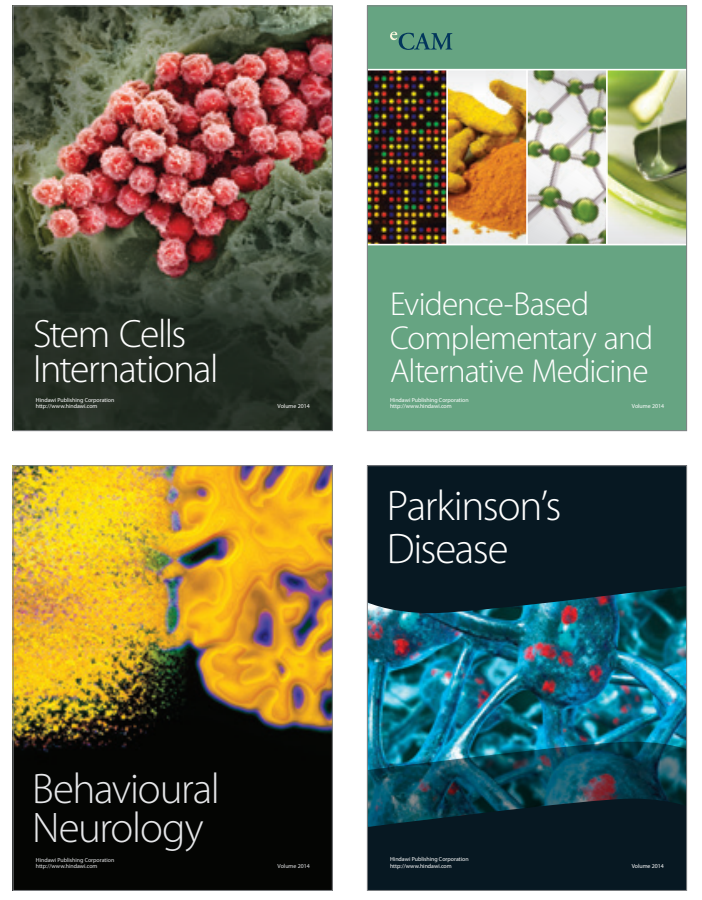
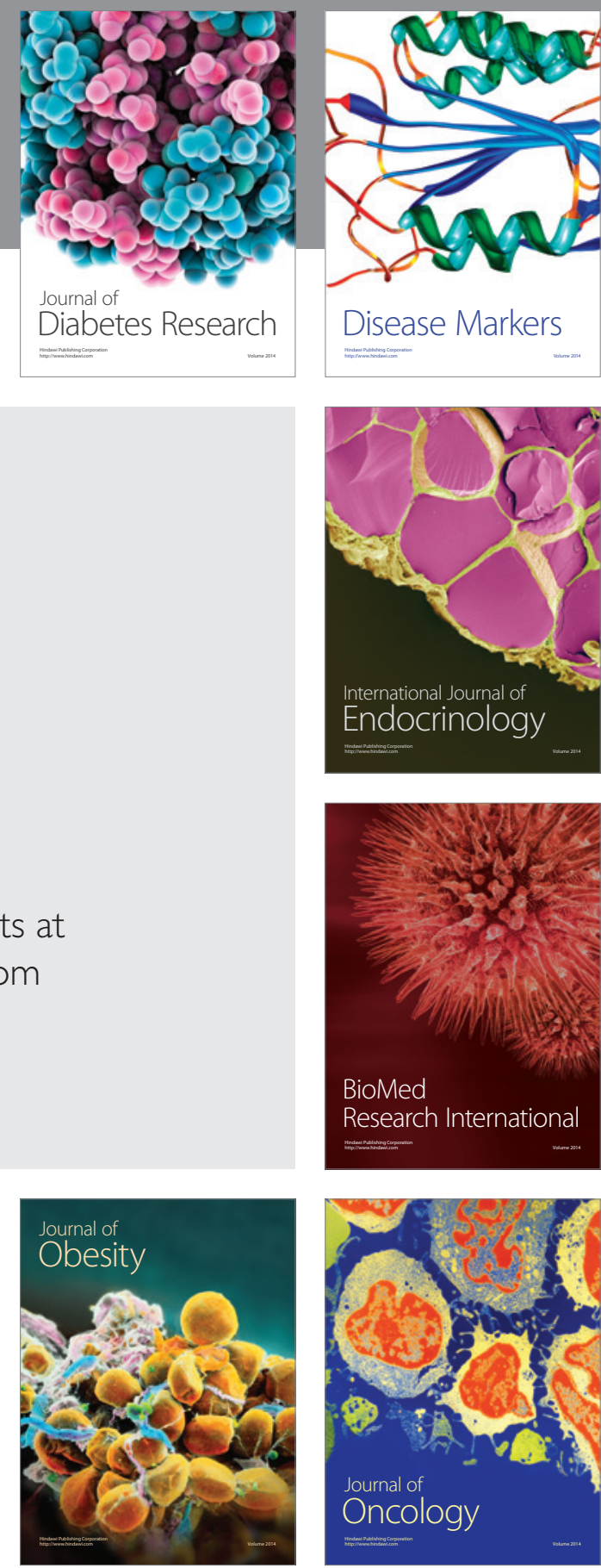

Disease Markers
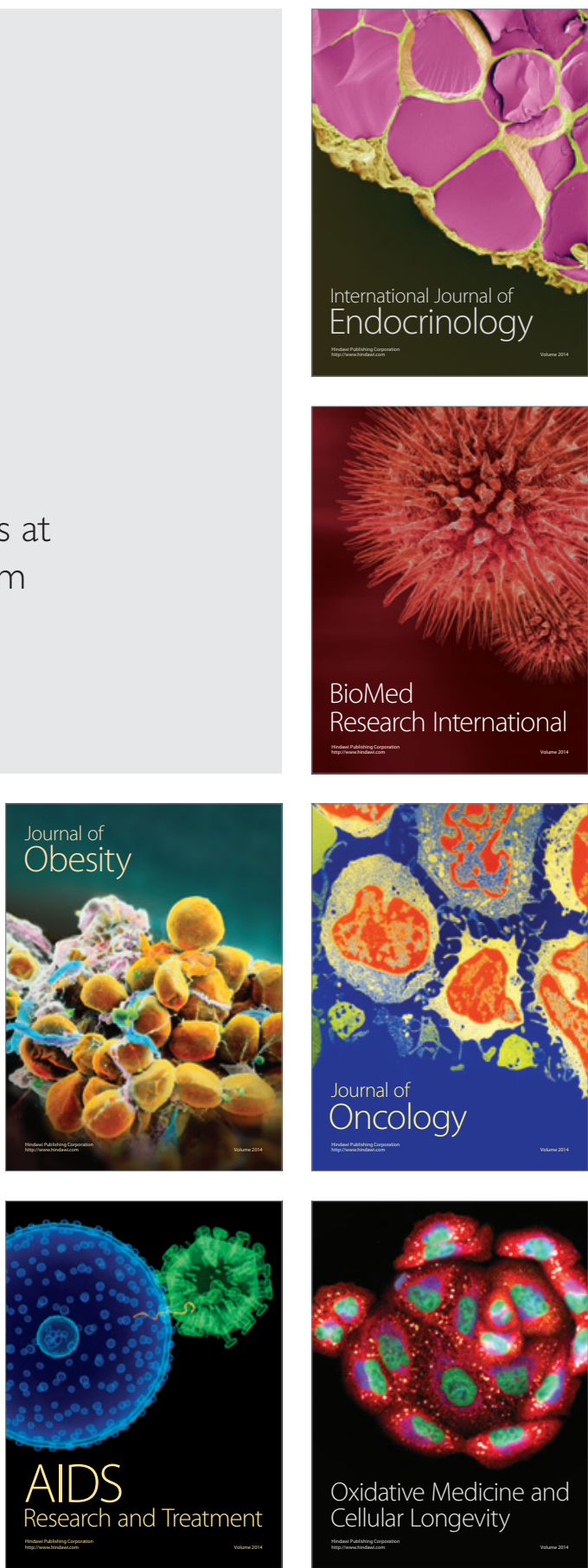